\title{
PENGARUH KUALITAS LAYANAN TERHADAP LOYALITAS NASABAH BANK SYARIAH DENGAN KEPUASAN NASABAH SEBAGAI VARIABEL INTERVENING
}

\author{
Muhammad Zakiy \\ Program Studi Ekonomi dan Perbankan Perbankan Islam, Fakultas Agama Islam, \\ Universitas Muhammadiyah Yogyakarta \\ Email: zakiy ishak@yahoo.com \\ Evrita Putri Azzahroh \\ Program Studi Ekonomi dan Perbankan Perbankan Islam, Fakultas Agama Islam, \\ Universitas Muhammadiyah Yogyakarta \\ Email: evrita.putri@gmail.com
}

\section{ARTICLE HISTORY}

Received:

10 February 2017

Accepted:

16 June 2017

Online available:

30 June 2017

Keywords:

Customer

Satisfaction,

Customer loyality,

Compliance,

Islamic Banking,

Muamalat Bank
ABSTRACT

This research aims to examine the role of customer satisfaction as a mediating variable to connecting service quality to customer loyalty in Islamic Banks. This study also tested compliance as the dimension for measure quality service in Islamic Bank. This research was conducted in five Islamic Banks which are in Indonesia. Data were collected using a questionnaire, distributed through are online and offline to the Islamic Bank customer. There are 100 questionnaires were successfully collected and analyzed using Structural Equation Modeling (SEM) to test the hypothesis with the application of Smart-PLS 3.0. the result of this study indicate that customer satisfaction is able to mediate (full mediation) in influence the service quality to customer loyalty in Islamic Banks.

\section{ABSTRAK}

Kata Kunci:

Kepuasan

Pelanggan,

Loyalitas

Nasabah,

Pemenuhan, Bank

Syariah, Bank

Muamalat
Penelitian ini bertujuan untuk menguji peran variabel pemediasi yaitu kepuasan nasabah yang menghubungkan antara kualitas layanan dengan loyalitas nasabah Bank Syariah. Penelitian ini juga menguji dimensi pengukuran yang dikhususkan untuk mengukur kualitas layanan dari Bank Syariah yaitu compliance. Penelitian ini dilakukan di 5 Bank Syariah yang berada di Indonesia. Data dikumpulkan menggunakan kuesioner, didistribusikan melalui online dan fisik ke nasabah Bank Syariah. Sebanyak 100 kuesioner berhasil dikumpulkan dan dianalisis menggunakan Structural Equation Modeling (SEM) untuk menguji hipotesis dengan aplikasi Smart-PLS 3.0. Hasil penelitian ini menunjukkan bahwa kepuasan nasabah mampu memediasi secara penuh (full mediation) pengaruh kualitas layanan terhadap loyalitas nasabah Bank Syariah. 


\section{PENDAHULUAN}

Perkembangan teknologi informasi menjadikan persaingan bisnis dalam lingkungan global semakin kompetitif dan semakin sulit. Banyaknya bermunculan pesaing baru dalam industri yang sama, menjadi ancaman bagi perusahaan yang sedang menjalankan bisnisnya. Lahirnya perbankan syariah di Indonesia, menjadikan perbankan konvensional semakin meningkatkan kualitas layanannya agar tidak kehilangan pangsa pasarnya. Kemudahan dalam mengakses fasilitas perbankan, menjadikan konsumen dengan mudah membedakan kualitas layanan dari sebuah bank dengan bank lain. Untuk itu, perbankan syariah harus bersaing ketat dalam meningkatkan kualitas layannya agar kepuasan yang berujung pada loyalitas pelanggan dapat tercapai.

Loyalitas pelanggan merupakan keadaan yang diharapkan oleh setiap perusahaan, terutama perusahaan jasa seperti perbankan. Tingginya loyalitas pelanggan, dapat mengindikasikan keberhasilan sebuah perusahaan. Loyalitas pelanggan didefinisikan sebagai keinginan yang kuat dari pelanggan untuk membeli kembali produk atau jasa dan tidak akan berpindah ke perusahaan lain (Oliver, 1999). Pelanggan yang loyal akan selalu melakukan pembelian ulang dikemudian hari, jika mereka membutuhkan produk atau jasa yang sama. Pendapat ini sejalan dengan penelitian Porral \& Lang (2015) yang membuktikan bahwa pelanggan yang loyal terhadap sebuah produk, akan berniat untuk membeli ulang produk tersebut di kemudian hari. Secara tidak langsung, loyalitas pelanggan dapat meningkatkan daya saing dari sebuah perusahaan. Melihat peran loyalitas pelanggan sangat krusial bagi perusahaan, banyak ahli telah memeriksa kontribusi penting loyalitas pelanggan bagi perusahaan (He \& Lai, 2014; Martinez et al., 2014; Lee \& Lee, 2013).

Kepuasan pelanggan merupakan faktor utama dalam membentuk loyalitas pelanggan. Para ahli telah membuktikan pengaruh positif kepuasan pelanggan terhadap loyalitas pelanggan (Haumann et al., 2014; Bejou, 2013; Ringle et al., 2011). Pelanggan yang puas akan membeli produk yang ditawarkan dan mempengaruhi calon pelanggan lain untuk membeli produk dan jasa dari sebuah perusahaan (Pollack, 2014). Sejalan dengan penelitian Bunker et al. (2013) yang membuktikan bahwa pelanggan yang puas akan menyarankan/berkata positif mengenai perusahaan kepada orang lain/word of mouth (WOM). Oliver, (1980). Mendefinisikan kepuasan pelanggan sebagai keadaan psikologis yang dirasakan oleh pelanggan terhadap produk berupa barang atau jasa yang ditentukan oleh perbedaan antara harapan yang dimiliki pelanggan dengan pengalaman mengkonsumsi produk atau layanan tersebut.

Untuk membentuk kepuasan pelanggan dan loyalitas pelanggan, perbankan syariah yang merupakan industri jasa, harus meningkatkan kualitas layanannya. Kualitas layanan didefinisikan sebagai sejauh mana layanan sebuah perusahaan memenuhi atau melebihi harapan pelanggan (Parasuraman et al., 1985; Zeithamel et al., 1996). Parasuraman et al. 
(1985) menjelaskan bahwa kualitas layanan dapat diukur dengan lima dimensi (SERVQUAL) yaitu, reliability (kehandalan), assurance (jaminan), tangibles (bukti langsung), empathy (empati) dan responsiveness (daya tanggap). Namun dalam perbankan syariah Othman \& Owen (2002) telah menambahkan satu dimensi lagi dari SERVQUAL yaitu compliance (pemenuhan) yang kemudian disingkat menjadi CARTER. Compliance adalah kepatuhan terhadap hukum-hukum dasar dalam bermuamalah. Untuk itu, produk yang ditawarkan oleh Bank Syariah harus sesuai dengan prinsip-prinsip Syariah.

Penambahan dimensi compliance ini dikarenakan perbankan syariah memiliki keunikan tersendiri dalam melayani nasabahnya. Kepatuhan perbankan syariah akan prinsip-prinsip bermuamalah yang telah diatur dalam Al-Quran dan Sunnah, menjadikan daya tarik tersendiri bagi nasabahnya. Penelitian mengenai kualitas layanan perbankan syariah belum banyak yang menggunakan compliance dalam mengukur kualitas layanan yang diberikan bank syariah kepada nasabah. Melihat perbankan Syariah merupakan lembaga keuangan yang islami, maka peneliti menganggap compliance merupakan hal yang penting untuk menilai kualitas layanan. Dalam rangka membuat pelanggan mempercayai layanan yang diberikan, maka pelanggan harus merasakan kualitas layanan sebagai hal yang positif. Gerson (2001) menjelaskan bahwa kepuasan adalah persepsi pelanggan bahwa harapannya telah terpenuhi atau terlampaui.

\section{LANDASAN TEORI}

Teori Pertukaran Sosial menjelaskan bahwa, seseorang akan membalas perlakuan orang lain termasuk organisasi dan perusahaan sesuai dengan dirinya diperlakukan oleh orang tersebut. Mengacu pada teori tersebut maka, nasabah akan menunjukkan perilaku loyal yang didahului oleh kepuasan seperti melakukan pembelian ulang dan merekomendasikan orang lain untuk menggunakan produk dari Bank Syariah, jika nasabah tersebut merasakan kualitas layanan Bank Syariah sesuai dengan harapannya. Begitupula sebaliknya, jika kualitas layanan Bank Syariah yang dipersepsikan nasabah buruk, maka nasabah akan membalasnya dengan melakukan perpindahan (switching) dan menceritakan keburukan Bank Syariah kepada orang lain. Hoyt et al. (2015) menjelaskan bahwa loyalitas nasabah merupakan hambatan nasabah untuk melakukan perpindahan (switching). Selain itu, tingginya kepuasan pelanggan juga dapat memprediksi kredibilitas perusahaan, reputasi dan bonus dari pemimpin perusahaan (Jin \& Yeo, 2011; O'Connell \& O' Sullivan, 2011).

\section{Kualitas layanan sebagai anteseden dari kepuasan nasabah}

Kualitas layanan yang diterima atau dirasakan (perceived service) pelanggan sesuai dengan yang diharapkan maka kualitas layanan tersebut akan dianggap baik dan memuaskan (Parasuraman et al., 1985). Pelayanan yang ramah, fasilitas yang bersih, kesesuaian layanan dengan prinsip syariah, serta penampilan fisik yang menarik dari karyawan Bank Syariah maka akan meningkatkan kepuasan nasabah dari Bank Syariah. Sejalan dengan pendapat Kotler \& Killer (2009) yang menjelaskan bahwa pelanggan yang mempersepsikan kualitas layanan yang baik maka akan merasa puas. Dimensi-dimensi kualitas layanan seperti compliance, assurance, reliability, tangibles, empathy, dan 
responsiveness, jika diperhatikan dengan baik oleh Bank Syariah, maka akan meningkatkan kepuasan dari nasabah tersebut.

Kualitas layanan telah dihubungkan dengan beberapa variabel output lainnya, seperti berhubungan positif dengan citra perusahaan (Gadot \& Cohen, 2015; Zameer et al., 2015; Leblanc \& Nguyen, 1996), nilai pelanggan (Zameer et al., 2015), kepuasan pelanggan (Dkudiene et al., 2015; Kian et al., 2013), loyalitas pelanggan (Kian et al., 2013), intensi membeli (Dkudiene et al., 2015) dan berhubungan negatif dengan switching (Zhang, 2009). Dari penelitian terdahulu diatas, dapat dikatakan bahwa kualitas layanan dapat meningkatkan daya saing sebuah perusahaan, terutama perusahaan jasa seperti perbankan. Untuk itu, manajer sebuah perusahaan harus memperhatikan kualitas layanan perusahaannya dengan baik agar dapat meningkatkan kepuasan pelanggan. Dari alasanalasan tersebut, maka peneliti merumuskan hipotesis pertama sebagai berikut:

Hipotesis 1: Kualitas layanan berpengaruh positif terhadap kepuasan nasabah.

\section{Kepuasan nasabah sebagai anteseden dari loyalitas nasabah}

Kepuasan nasabah merupakan indikator utama terjadinya loyalitas nasabah. Nasabah yang merasa puas terhadap layanan bank Syariah akan mentransformasikan perasaannya tersebut menjadi loyalitas yang ditunjukkan dengan pembelian kembali secara konsisten dan menyarankan kepada orang lain untuk membeli produk dan layanan dari Bank Syariah. Pelanggan yang merasa puas dengan nilai yang diberikan oleh produk atau jasa maka besar kemungkinan pelanggan tersebut akan menjadi loyal dalam waktu yang lama (Umar 2000). Penelitian terdahulu telah membuktikan kontribusi dari kepuasan pelanggan antara lain, berpengaruh positif terhadap citra perusahaan (Kian et al., 2013), pembelian kembali (Dkudiene et al., 2015), nilai pelanggan (Zameer et al., 2015), loyalitas pelanggan (Mohsan et al., 2011; Andreassen \& Lindestad, 1998) dan perpengaruh negatif dengan switching intention (Martins et al., 2013; Zhang et al., 2012; Mohsan et al., 2011; Walsh \& Dinnie, 2006). Dari pemaparan penelitian terdahulu diatas, maka peneliti merumuskan hipotesis kedua sebagai berikut:

Hipotesis 2: Kepuasan Nasabah berpengaruh positif terhadap loyalitas nasabah

Peran variabel pemediasi kepuasan nasabah terhadap pengaruh kualitas layanan pada loyalitas nasabah

Bank Syariah sebagai lembaga dalam bidang jasa tentunya harus meningkatkan dan mengoptimalkan kualitas layanan untuk membangun loyalitas nasabah. Nasabah yang merasa nyaman, aman, diperhatikan kebutuhannya dan kesesuaian bank dengan prinsipprinsip Islam yang merupakan bagian dari kualitas layanan, akan merasakan kepuasan yang berujung pada loyalitas. Robbins \& Judge (2013) menjelaskan bahwa sikap seseorang dibentuk dari tiga komponen yaitu, kognitif/evaluasi, afektif/perasaan dan perilaku/tindakan. Dapat dikatakan bahwa persepsi/evaluasi nasabah terhadap kualitas layanan yang diberikan Bank syariah, akan memunculkan perasaan puas/kognitif yang akan menentukan loyalitas/tindakan dari nasabah. Dengan kata lain, nasabah akan merekomendasikan orang lain dan melakukan pembelian ulang jika nasabah tersebut 
merasa puas akan produk dan layanan dari Bank Syariah. Untuk itu, peneliti merumuskan hipotesis ketiga sebagai berikut:

Hipotesis 3: Kepuasan nasabah memediasi pengaruh kualitas layanan terhadap loyalitas nasabah

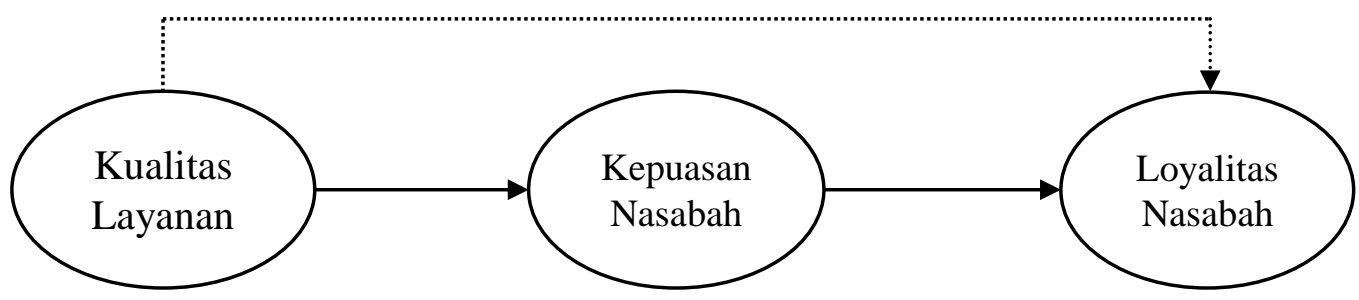

\section{Gambar 1.}

Kerangka konseptual pembentukan hipotesis

Dari gambar 1 diatas dapat diartikan bahwa kualitas layanan yang dipersepsikan nasabah terhadap layanan yang diberikan oleh karyawan bank syariah, berpengaruh positif terhadap kepuasan nasabah Bank Syariah. Selain itu peneliti juga akan memeriksa pengaruh kepuasan nasabah terhadap loyalitas nasabah Bank Syariah. Penelitian ini juga akan melihat apakah kepuasan nasabah memediasi penuh kualitas layanan terhadap loyalitas nasabah.

\section{METODE PENELITIAN}

\section{Sampel dan Prosedur}

Responden dalam penelitian ini adalah nasabah lima Bank Syariah di Indonesia, kreteria responden yang dipilih yaitu nasabah yang mempunyai rekening di 5 Bank Syariah minimal 2 tahun, nasabah yang telah bertransaksi selama 2 tahun dipilih karena seseorang yang sudah menjadi nasabah selama 2 tahun diharapkan mengetahui secara mendalam mengenai kualitas layanan, manfaat dan biaya selama menjadi nasabah bank. Peneliti membagikan 100 kuesioner offline dan menyebar link kuesioner secara online. Kuesioner yang terkumpul sebanyak 150 dan kuesioner yang dapat diolah sebanyak 100 kuesioner (tingkat respon 66,67\%). Banyaknya kuesioner yang tidak dapat diolah karena kebanyakan dari responden belum menjadi nasabah di Bank Syariah selama 2 tahun. Selain itu, banyak responden yang memiliki tabungan Bank Syariah tetapi diluar dari 5 bank yang telah ditentukan oleh peneliti dan ketidaklengkapan responden dalam mengisi kuesioner, sehingga kuesioner harus dikeluarkan.

Dalam penelitian ini, responden dengan jenis kelamin pria sebanyak 36 responden (36\%) dan sisanya 64 responden berjenis kelamin wanita (64\%). Status responden di Bank Syariah didominasi oleh penabung yaitu sebanyak 91 responden (91\%) dan yang paling sedikit yaitu lainnya sebanyak 1 responden (1\%). Untuk status usia responden terbanyak yaitu berkisar antara 21 sampai 25 tahun sebanyak 75 responden (75\%) dan untuk usia 26 sampai 30 tahun sebanyak 5 responden (5\%). Untuk status pekerjaan dan pendidikan terakhir didominasi oleh mahasiswa dan pendidikan terakhir SMA masing-masing sebanyak 
80 (80\%) dan 68 (68\%) responden. untuk kategori lama menjadi nasabah didominasi oleh responden 2 sampai 5 tahun yaitu sebanyak 88 responden (88\%) dan yang paling sedikit yaitu nasabah 5,1 tahun sampai 7 tahun sebanyak 3 responden (3\%). Untuk variabel demografi terakhir yaitu pendapatan didominasi oleh responden dengan pendapatan dibawah 1 juta dan yang paling sedikit yaitu diatas 10 juta.

\section{Pengukuran}

Seluruh Pengukuran kuesioner dalam penelitian ini menggunakan skala Likert. 5 point. Untuk variabel kualitas layanan dalam penelitian ini skor " 1 " mewakili sangat tidak penting dan skor " 5 " mewakili sangat penting. Untuk variabel kepuasan nasabah dan loyalitas nasabah skor "1" mewakili sangat tidak setuju, dan skor "5" mewakili sangat setuju. Peneliti menggunakan metode back-translation untuk memastikan terjemahan yang benar dari setiap pernyataan yang disesuaikan dalam bahasa Indonesia.

Kualitas layanan. Peneliti menggunakan 24 item pernyataan yang dikhususkan untuk mengukur kualitas layanan yang terdapat di Bank Syariah meliputi Compliance, Assurance, Reliability, Tangibility, Empathy dan Resposiveness (CARTER). Item-item pernyataan ini dikembangkan oleh Otman \& Owen (2002). Contoh dari pernyataannya adalah "Bank Syariah sesuai dengan hukum dan prinsip-prinsip Islam". Koefisien crombath alpha dalam variabel ini adalah 0,962.

Kepuasan nasabah. Peneliti menggunakan 6 item pernyatan yang dikembangkan oleh Oliver (1980). Contoh dari pernyataannya adalah "saya merasa puas dan senang setiap kali bertransaksi di Bank Syariah". Koefisien crombath alpha dalam variabel ini adalah 0,851.

Loyalitas nasabah. Untuk mengukur variabel ini, peneliti menggunakan 7 item pernyataan yang dikembangkan oleh Anderson \& Swaminathan (2011). Contoh item pernyataannya adalah "Saya tidak pernah memikirkan untuk beralih ke layanan bank lain". Koefisien crombath alpha dalam variabel ini adalah 0,921.

\section{Tabel 1}

Mean, dan Koefisien Korelasi Antar Variabel

\begin{tabular}{ccccc}
\hline Variabel & $\mathbf{M}$ & $\mathbf{K L}$ & $\mathbf{K N}$ & $\mathbf{L N}$ \\
\hline $\mathrm{KL}$ & 4,08 & & & \\
$\mathrm{KN}$ & 3,92 & $0,267^{* *}$ & & \\
$\mathrm{LN}$ & 3,49 & $0,330^{* *}$ & $0,621^{* *}$ & 1 \\
\hline
\end{tabular}

** Correlation is significant at the 0,01 level (2-tailed)

Keterangan:

KL : Kualitas Layanan

KN : Kepuasan Nasabah

LN : Loyalitas Nasabah 


\section{HASIL DAN PEMBAHASAN}

\section{Analisis Faktor}

\section{Model Pengukuran}

Uji validitas dalam penelitian ini menggunakan analisis faktor konfirmatori dengan menggunakan softwer SmartPLS 3.0. Uji validitas dalam PLS dengan melihat convergent validity dari model pengukuran dengan menggunakan indikator reflektif dinilai berdasarkan loading factor indikator-indikator yang mengukur konstruk tersebut. Jika nilai faktor loading $\leq 0,5$, maka indicator tersebut harus didrop. Standar untuk faktor loading dalam convergent validity adalah 0,5 dan lebih baik jika faktor loadingnya $\geq 0,7$. Discriminant validity berfungsi untuk mengukur ketepatan model reflektif dan untuk nilai AVE dari discriminant validity dipatok angka minimal 0,5 dan hasil yang lebih baik yaitu lebih dari 0,5.

Covergent validity dari model pengukuran dengan menggunakan indikator reflektif dinilai berdasarkan loading factor indikator-indikator yang mengukur konstruk tersebut. Gambar 2 menunjukkan terdapat tiga variabel dengan jumlah indikator 37, yaitu 24 indikator untuk kualitas layanan, 6 indikator untuk kepuasan nasabah dan 7 indikator untuk loyalitas nasabah. Berdasarkan hasil pengujian model pengukuran seluruh indikator memiliki faktor loading lebih dari 0,5, AVE $\geq 0,5$ yakni 0,536 untuk konstruk kualitas layanan, 0,545 untuk konstruk kepuasan nasabah dan 0,684 untuk konstruk loyalitas nasabah. Untuk pengukuran discriminant validity yaitu dinilai berdasarkan cross loading pengukuran dengan konstruknya atau dengan membandingkan akar AVE. Dalam pengujian ini, nilai akar kuadrat dari AVE yaitu masing masing sebesar 0,732 untuk kualitas layanan, 0,738 untuk kepuasan nasabah dan 0,827 untuk loyalitas nasabah. Nilai-nilai tersebut juga lebih besar dari masing-masing korelasi antar konstruk.

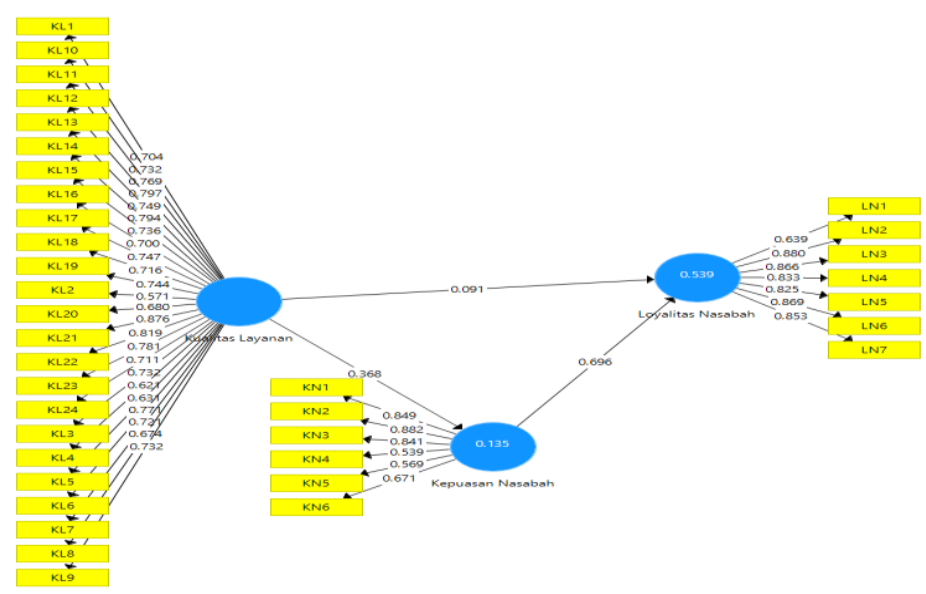

Gambar 2

Output Outer model 


\section{Pengujian Hipotesis}

\section{Model Struktural}

Pengujian model struktural (Inner model) dilakukan dengan melihat nilai koefisien jalur dan nilai signifikansi ( $p$-value). Adapun rangkuman nilai koefisien jalur untuk setiap hipotesis dirangkum pada gambar 3 dan tabel 2.

Hipotesis 1 yang menyatakan kualitas layanan berpengaruh positif terhadap kepuasan nasabah Bank Syariah. Hasil pengujian model struktural menunjukan bahwa kualitas layanan berpengaruh positif signifikan terhadap kepuasan nasabah dengan nilai koefisien sebesar 0,368 dan T-value 2,647, dengan tingkat signifikansi sebesar $\leq 0,05$. Hasil ini pengujian ini memberi dukungan untuk hipotesis pertama. Hasil penelitian ini konsisten dengan penelitian terdahulu yang dilakukan oleh Dkudiene et al. (2015) dan Kian et al. (2013).

Hipotesis 2 yang menyatakan kepuasan nasabah berpengaruh positif terhadap loyalitas nasabah. Hasil uji hipotesis menunjukan jalur yang menghubungkan kepuasan nasabah dengan loyalitas nasabah memiliki nilai koefision sebesar 0,696 dan T-value 9,632 dengan tingkat signifikansi $\leq 0,001$. Hal ini mendukung hipotesis kedua. Hasil penelitian ini sejalan dengan penelitian Mohsan et al. (2011) dan Andreassen \& Lindestad (1998).

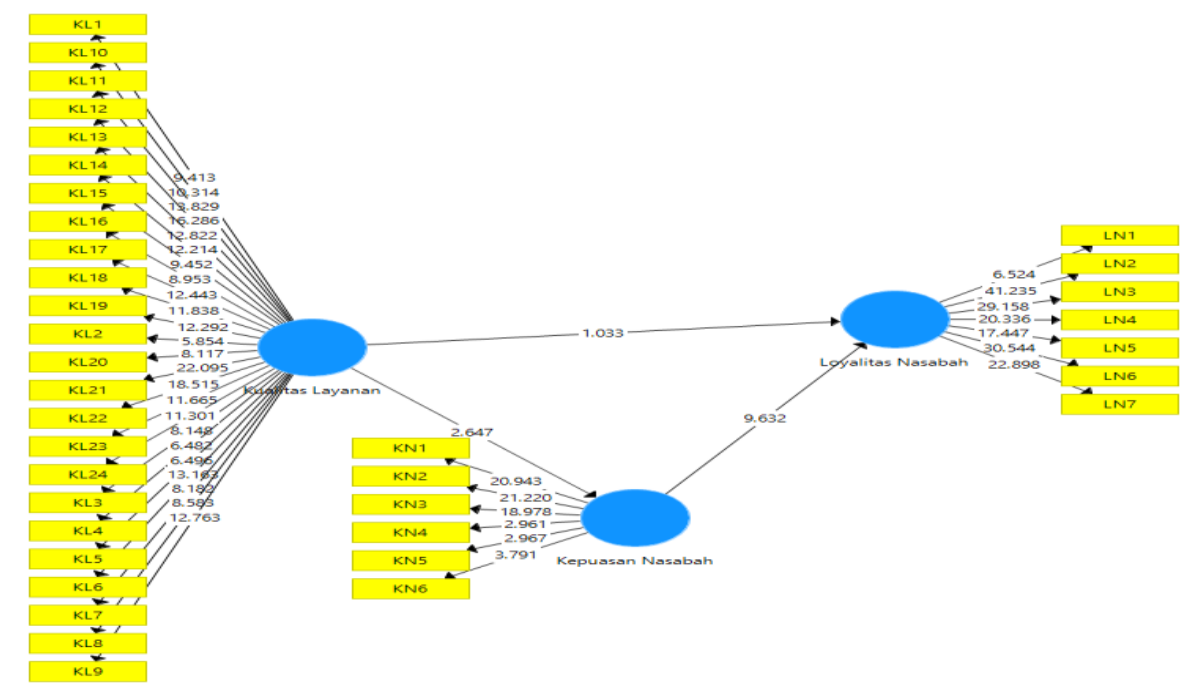

Gambar 3

Output Inner model 
Tabel 2

Hasil Pengujian Hipotesis

\begin{tabular}{|c|c|c|c|}
\hline Keterangan & B & $\mathbf{T}$ & $\boldsymbol{P}$ \\
\hline Kualitas Layanan $\rightarrow$ Kepuasan Nasabah & 0,368 & 2,647 & $0,008 * *$ \\
\hline Kepuasan Nasabah $\rightarrow$ loyalitas Nasabah & 0,696 & 9,632 & $0,000 * * *$ \\
\hline Kualitas Layanan $\rightarrow$ Loyalitas Nasabah & 0,091 & 1,033 & 0,302 \\
\hline
\end{tabular}

Hipotesis 3 yang menyatakan kepuasan nasabah memediasi pengaruh kualitas layanan terhadap loyalitas nasabah, dapat dilihat pengaruh predictor (kualitas layanan) terhadap criterion (loyalitas nasabah) dengan tetap memasukan pengaruh mediasi (Kepuasan nasabah). Dari pengujian tampak bahwa ketika pengaruh dari mediator dimasukan pada model terlihat bahwa kualitas layanan memiliki pengaruh yang signifikan terhadap loyalitas nasabah. Hal ini berbeda dengan langkah ketika variabel mediasi tidak dimasukan kedalam model. Dengan hilangnya pengaruh langsung dari predictor (kualitas layanan) terhadap criterion (loyalitas nasabah) dapat dinyatakan bahwa kepuasan nasabah memiliki pengaruh mediasi sempurna (full mediation). Hasil pengujian ini mendukung hipotesis ketiga kami.

Tujuan utama dalam penelitian ini adalah untuk melihat peran variabel pemediasi yaitu kepuasan nasabah dalam pengaruh kualitas layanan terhadap loyalitas nasabah. Kepuasan nasabah dapat memberikan manfaat, diantaranya hubungan antara perbankan dengan nasabah menjadi harmonis, memberikan dasar yang baik bagi pembelian ulang, terciptanya loyalitas nasabah dan membentuk suatu rekomendasi dari mulut kemulut (word of mouth) yang menguntungkan bagi perusahaan (Tjiptono, 2014). Selain itu studi empiris lainnya juga membuktikan meningkatkan kualitas layanan terhadap konsumen yaitu dengan menerapkan customer relationship marketing melalui komitmen melayani, komunikasi dengan pelanggan dan penanganan keluhan konsumen sebagai fokus dalam membangun hubungan baik dengan konsumen (Ndubisi, 2007).

Hasil pengujian model struktural menunjukkan dukungan untuk hipotesis pertama. Kualitas layanan berpengaruh positif terhadap kepuasan nasabah. Pelayanan yang cepat, aman, nyaman, sopan, tampilan yang manarik dari karyawan dan tampilan fisik perbankan serta kesesuaian Bank Syariah dengan prinsip-prinsip syariah, maka nasabah akan merasakan kepuasan. Hasil penelitian ini konsisten dengan penelitian terdahulu yang membuktikan bahwa kualitas layanan berpengaruh positif dengan kepuasan nasabah (Dkudiene et al., 2015; Kian et al., 2013).

Hipotesis kedua dalam penelitian ini yang menyatakan bahwa kepuasan nasabah berpengaruh positif terhadap loyalitas nasabah didukung. Nasabah yang merasakan perasaan puas terhadap layanan dan produk dari Bank Syariah, maka nasabah tersebut akan 
mentransformasikannya kedalam perilaku seperti pembelian ulang, merekomendasikan kepada orang lain dan berkata positif mengenai Bank Syariah. Hasil ini sejalan dengan penelitian terdahulu yang menyatakan bahwa kepuasan nasabah berpengaruh positif terhadap loyalitas nasabah (Mohsan et al., 2011; Andreassen \& Lindestad, 1998).

Hasil pengujian juga menunjukan dukungan untuk hipotesis ketiga yang menyatakan bahwa kepuasan nasabah memediasi pengaruh positif kualitas layanan terhadap loyalitas nasabah. Mengacu pada teori pertukaran sosial bahwa seseorang akan membalas perlakuan orang lain termasuk perusahaan terhadap dirinya seperti apa yang perusahaan perlakukan /berikan kepadanya. Nasabah yang merasakan kepuasan dari pelayanan yang diberikan Bank Syariah, maka nasabah tersebut akan membalas perilaku Bank Syariah dengan menunjukan loyalitas seperti pembelian ulang, merekomendasikan kepada orang lain dan berkata positif mengenai Bank Syariah. Selain itu, peran variabel pemediasi ini juga mendukung pendapat Robbins \& Judge (2013) yang menjelaskan bahwa sikap seseorang dibentuk dari tiga komponen yaitu, kognitif/evaluasi, afektif/perasaan dan perilaku/tindakan. Dapat dikatakan bahwa persepsi/evaluasi nasabah terhadap kualitas layanan yang diberikan Bank syariah, akan memunculkan perasaan puas/kognitif yang akan menentukan loyalitas/tindakan dari nasabah.

Berdasarkan konteks penelitian ini, maka dapat dikatakan bahwa kualitas layanan yang diberikan Bank Syariah dengan mematuhi prinsip-prinsip syariah akan meningkatkan kepuasan nasabah yang berujung pada loyalitas nasabah 5 Bank Syariah yang berada di Indonesia. Masyarakat Indonesia yang mayoritas beragama Islam juga menjadi peluang untuk meningkatkan pangsa pasar dari Bank Syariah dengan cara meningkatkan kualitas layanannya. Selain itu, hasil penelitian ini juga menunjukkan pencapaian yang sangat memuaskan dari Bank Syariah, jika dilihat dari eksistensi Bank Syariah yang relatif baru jika dibandingkan dengan Bank Konvensional.

\section{Implikasi Penelitian}

Implikasi Teoritis. Hasil penelitian ini dapat dijadikan bukti empiris yang menjelaskan pengaruh positif kualitas layanan terhadap kepuasan nasabah dan pengaruh positif kepuasan nasabah terhadap loyalitas nasabah. Selain itu, hasil penelitian ini menunjukan peran variabel mediasi kepuasan kerja yang menghubungkan kualitas layanan terhadap loyalitas nasabah. Penelitian ini juga dapat dijadikan acuan untuk penelitian selanjutnya dengan tema yang sama yaitu loyalitas nasabah Bank Syariah.

Implikasi Praktis. Hasil dari penelitian ini memberikan kontribusi yang sangat penting bagi para pengambil kebijakan dalam perusahaan, khususnya dalam bidang pemasaran bank di 5 Bank Syariah yang diteliti. Hasil penelitian ini menunjukan kualitas layanan berpengaruh positif terhadap kepuasan nasabah yang berujung pada loyalitas nasabah. Peran karyawan dalam memberikan pelayanan dapat mempengaruhi tinggi-rendahnya kepuasan nasabah. Selain itu, penelitian ini dilakukan di 5 Bank Syariah, sehingga dapat dikatakan bahwa penelitian ini memiliki tingkat generalisasi yang tinggi. 
Pengaruh Kualitas Layanan...

\section{SIMPULAN}

Penelitian ini memiliki beberapa kelemahan yang harus diperbaiki dalam penelitian selanjutnya. Pertama, penelitian ini hanya menggunakan variabel loyalitas nasabah sebagai variabel dependen, sehingga kontribusi kualitas layanan dan kepuasan nasabah terhadap variabel output lain tidak dapat dilihat. Penelitian selanjutnya dapat menambahkan variabel dependen lainnya seperti switching dan citra perusahaan. Kedua, jumlah responden dalam penelitian ini hanya 100 responden dan mayoritas dari kalangan mahasiswa yang mewakili 5 Bank Syariah, sehingga data yang diperoleh kurang mewakili responden Bank Syariah secara keseluruhan. Penelitian selanjutnya disarankan agar dapat menambahkan jumlah responden dan mendistribusikannya ke semua kalangan agar hasilnya lebih dapat mewakili. Ketiga, penelitian ini hanya menggunakan data kuantitatif, sehingga tidak bisa menganalisis secara mendalam mengenai kenapa dan bagaimana hubungan antar variabel dapat terjadi. Penelitian selanjutnya diharapkan dapat melakukan metode gabungan (trianggulasi) yaitu metode kuantitatif kualitatif agar dapat memperoleh analisis yang mendalam.

\section{DAFTAR PUSTAKA}

Anderson, R. E., \& Swaminathan, S. (2011). Customer satisfaction and loyalty in e-markets: A PLS path modeling approach. Journal of Marketing Theory and Practice, 19/2, 221234. doi: 10.2753/MTP1069-6679190207.

Andreassen, T. W., \& Lindestad, B. (1998). Customer loyalty and complex services: The impact of corporate image on quality, customer satisfaction and loyalty for customers with varying degrees of service expertise. International Journal of Service Industry Management, 9/1, 7-23. doi: 10.1108/09564239810199923.

Bejou, A. (2013). An empirical investigation of the correlates of satisfaction in public schools. Journal of Relationship Marketing, 12: 243-260. doi: 10.1080/15332667.2013.846721.

Bunker, M. P., Rajendran, K. N., \& Corbin, S. B. (2013). The antecedents of satisfaction for Facebook "likers" and their effect on word of-mouth. The Marketing Management Journal, 23/2, 21-34.

Dkudiene, V., Eertokas, D., McCorkle, D., \& Reardon, J. (2015). The effect of e-shops' service quality on Lithuanian consumers' purchase intentions. International Journal of Business, Marketing, and Decision Sciences, 8/1, 43-59.

Gadot, E. V., \& Cohen, H. (2015). Service satisfaction and organizational image, An empirical examination of the relationship with support for NPM-style reforms. Transforming Government: People, Process and Policy, 9/1, 2-16. doi: 10.1108/TG-02-2014-0004.

Gerson, R. F. (2001). Mengukur kepuasan pelanggan, panduan menciptakan pelanggan bermutu. Jakarta: PPM 
Haumann, T., Quaiser, B., Wieseke, J., \& Rese, M. (2014). Footprints in the sands of time: A comparative analysis of the effectiveness of customer satisfaction and customercompany identification over time. Journal of Marketing, 78, 78-102. doi: 10.1509/jm.13.0509.

He, Y., \& Lai, K. K. (2014). The effect of corporate social responsibility on brand loyalty: the mediating role of brand image. Total Quality Management, 25/3, 249-263. doi:10.1080/14783363.2012.661138.

Hoyt, B. R., McCullough, T., Callihan, E., \& Bibber, A. V. (2015). The impact of cause related marketing on customer loyalty: a case study on cause fit and switching barriers for retail banks. International Journal of Business, Marketing, and Decision Sciences, $8 / 1,1-21$.

Jin, C. H., \& Yeo, H. C. (2011). Satisfaction, corporate credibility, CEO reputation and leadership effects on public relationships. Journal of Targeting, Measurement and Analysis for Marketing, 19/2, 127-140. doi: 10.1057/jt.2011.10.

Kian, T. P., Suradi, N. R. M., \& Saludin, M. N. (2013). The impact of complaint management and service quality on organizational image: A case study at the Malaysian public university library. Proceedings of the 20th National Symposium on Mathematical Science, 1522, 1447-1453. doi: 10.1063/1.4801300.

Kotler, P., \& Keller, K. L. (2009). Manajemen Pemasaran. Jakarta: Erlangga.

Leblanc, G., \& Nguyen, N. (1996). Cues used by customers evaluating corporate image in service firms, An empirical study in financial institutions. International Journal of Service Industry Management, 7/2, 44-56. doi: 10.1108/09564239610113460.

Lee, J., \& Lee, H. (2013). Does satisfaction affect brand loyalty?. Academy of Marketing Studies Journal, 17/2, 133-147.

Martinez, P., Perez A., \& Bosque, I. R. (2014). CSR influence on hotel brand image and loyalty. Academia Revista Latinoamericana de Administración, 27/2, 267-283. doi: 10.1108/ARLA-12-2013-0190.

Mohsan, F., Nawaz, M. M., Khan, M. S., Shaukat, Z., \& Aslam, N. (2011). Impact of customer satisfaction on customer loyalty and intentions to switch: Evidence from banking sector of Pakistan. International Journal of Business and Social Science, 2/16, 263270.

Ndubisi, N. O. (2007). Relationship marketing and custemer royality. Marketing Intelligance \& Planning, 25, 98-106.

O'Connell, V., \& O'Sullivan, D. (2011). The impact of customer satisfaction on CEO bonuses. Academy of Marketing Science, 39, 828-845. doi: 10.1007/s11747-010-0218-1

Oliver, R. L. (1999). Whence consumer loyalty?. Journal of Marketing, 63, 33-44. 
Pengaruh Kualitas Layanan...

Oliver, R. L. (1980). A cognitive model of the antecedents and consequences of satisfaction decisions. Journal of Marketing Research, 17, 460-469.

Othman, A. Q., \& Owen, L. (2002). Adopting and measuring custemer servise quality (SQ) in Islamic Banking: A case study in Kuwait finance house. Internasional Jurnal of Islamic Financial Servise, 3/1, 1-26.

Parasuraman, A., Zeithaml, V. A., \& Berry, L.L. (1985). A conceptual model of service quality and its implications for future research. Journal of Marketing, 49/4, 41-50. doi: $10.2307 / 1251430$.

Pollack, B. L. (2014). Why do consumers stay when things are bad and leave when things are good?. Journal of Relationship Marketing, 13, 191-206. doi: 10.1080/15332667.2014.939016.

Porral, C. C., \& Lang, M. F. (2015). Private labels, The role of manufacturer identification, brand loyalty and image on purchase intention. British Food Journal, 117/2, 506-522. doi: 10.1108/BFJ-06-2014-0216.

Ringle, C. M., Sarstedt, M., Zimmermann, L. (2011). Customer satisfaction with commercial airlines: the role of perceived safety and purpose of travel. Journal of Marketing Theory and Practice, 19/4, 459-472. doi: 10.2753/MTP1069-6679190407

Robbins, S. P., \& Judge, T. A. (2013). Organizational behaviour. (Fifteenth Edition). London: Pearson.

Tjiptono, F. (2014). Pemasaran Jasa. Yogyakarta : Andi.

Umar, H. (2000). Riset pemasaran dan perilaku konsumen, Jakarta: Kompas Gramedia.

Walsh, G., \& Dinnie, K. (2006). How do corporate reputation and customer satisfaction impact customer defection? A study of private energy customers in Germany. Journal of Services Marketing, 20/6, 412-420. doi: 10.1108/08876040610691301

Zameer, H., Tara, A., Kausar, U., \& Mohsin, A. (2015). Impact of service quality, corporate image and customer satisfaction towards customers' perceived value in the banking sector in Pakistan. International Journal of Bank Marketing, 33/4, 442-456. doi: 10.1108/IJBM-01-2014-0015.

Zeithaml, V. A., Berry, L. L., Parasuraman, A. (1996). The behavioral consequences of service quality. Journal of Marketing, 60/2, 31-46. doi: 10.2307/1251929.

Zhang, D. (2009). Customer switching behaviour in the Chinese retail banking industry. Lincoln University, Canterbury, New Zealand. 